\title{
Unpacking Climate Impacts and Vulnerabilities of Cotton Farmers in Pakistan: A Case Study of Two Semi-arid Districts
}

\author{
Samavia Batool ${ }^{1} \cdot$ Fahad Saeed $^{1,2,3}$
}

Received: 5 April 2018 / Revised: 1 August 2018 / Accepted: 2 August 2018 / Published online: 14 August 2018

(C) The Author(s) 2018

\begin{abstract}
This paper aims to contribute to the understanding of climate risks and vulnerability facing cotton farmers in semi-arid regions of Pakistan. Given the ever-increasing climate change impacts on cotton production in Pakistan, especially in semiarid regions where water scarcity puts additional pressure on water sensitive agricultural livelihoods, we have conducted this study to identify climate risks facing cotton farmers in two semi-arid districts of Punjab province (average annual contribution to total cotton production is $80 \%$ ), based on various climate indicators (such as temperature, rainfall and climate extremes.). A mix of qualitative and quantitative methods has been used to explore factors of vulnerability and comparative vulnerabilities. In the cotton production stage, we found that vulnerability to climate change decreases with increase in the size of the landholding, mainly because large farmers have more financial resources at their disposal to deal with adverse climate impacts, such as crop damages and losses. Adaptive capacity, on the other hand, is found to be one of the significant factors determining the overall vulnerability at the household level, as level of exposure and sensitivity do not differ across different sized households. In other words, indicators of adaptive capacity, such as access to financial resources, diversified livelihoods and access to weather information plays a major role in reducing vulnerability against climate change.
\end{abstract}

Keywords Vulnerability $\cdot$ Adaptation $\cdot$ Value chain $\cdot$ Climate change

\section{Introduction}

Climate change is exacerbating the existing challenges of the agriculture sector (IPCC 2014), especially for agro-based economies, such as Pakistan, which has severe implications for productivity, livelihoods and economic growth (Siddique et al. 2012). Agriculture is the backbone of Pakistan's economy. It accounts for $19.5 \%$ of the gross domestic product (GDP), employs $42.3 \%$ of the total labour force and provides raw material for several value-added sectors ( $(\mathrm{GoP})$ Government of Pakistan 2017). Within agriculture, cotton is one of the major sectors driving economic growth of the country. It contributes $5.2 \%$ to the agricultural value addition and

Samavia Batool

samavia@sdpi.org

1 Sustainable Development Policy Institute, Islamabad, Pakistan

2 Center for Excellence in Climate Change Research, King Abdul-Aziz University, Jeddah, Saudi Arabia

3 Climate Analytics, Berlin, Germany has a share of $1.0 \%$ in the GDP of Pakistan ((GoP) Government of Pakistan 2017). While cotton production declined significantly during 2015-2016, primarily due to flood (a major impact of climate change), the policy focus has shifted to agriculture and especially to the cotton sector. This is also in recognition that climate change is projected to exacerbate risks in the future, which would have serious implications for the export economy of Pakistan (Batool and Saeed 2017). Moreover, textile industry, a major industrial sector of the country, is largely dependent on the cotton crop for production and hence any adverse impact on local cotton crop has implications for textile sector (in the form of reduced input supply) and in turn, for the national economy (Batool and Saeed 2017).

Studies based on the station observations found an increasing trend of temperature in Pakistan (Río et al. 2013; Sheikh et al. (2009); ADB (2017); Sadiq and Qureshi (2010); Khattak and Ali 2015; Ali et al. 2016). Moreover, future projections based on climate modelling also suggest a continuation of this trend (Batool and Saeed 2017; Saeed and Athar 2017). Besides mean temperature, climate extremes such as heat waves also show an increasing trend 
both in the past and in future projection for Pakistan (Maida and Rasul 2010; Saeed et al. 2017). Furthermore, studies also point towards an increase in temporal and spatial variability of precipitation both in the past as well as future (Ali et al. 2016; Ikram et al. 2016; Salma et al. 2012; Hussain and Lee (2014); Siddique et al. 2012). This has consequences not only in terms of droughts and dry spells, but combine effect of snow/ice melting and heavy monsoon precipitation makes the country very vulnerable to flooding events. As a result of these climate impacts, there are a huge number of reported evidences of increased poverty, food insecurity and health deterioration (Asian Development Bank 2017). Not only this, livestock, forestry, water, energy, transport and agriculture sector in particular have found to be adversely affected by climate change to a large extent (Asian Development Bank 2017). This in turn, have huge implications for the livelihoods of millions of people associated with these sectors and their value chains ${ }^{1}$ (Batool and Saeed 2017).

Cotton is considered to be a highly sensitive crop and climate change (both gradual change and extreme events) is expected to have profound impacts on its productivity (Ton 2011). Cotton crop is particularly vulnerable to high temperatures, $\mathrm{CO}_{2}$ concentration in the atmosphere, low water availability, high atmospheric evaporation rate and heat stress (MacKerron 2001; Richardson et al. 2002; Singh et al. 2007; Bange 2007). A comparative analysis of climate impact on cotton crop across several countries, including China, Pakistan, Australia, the US and Brazil among others, indicates that a likely decrease in rainfall along with rising temperatures will likely cause the cotton's demand for water to increase in all of the study areas (Ton 2011). While the pace of glacial depletion is getting faster, there is a likelihood that water in the Indus River (shared by Pakistan, India and China), which is a major source of irrigation for nearby cotton producing regions, would start to run dry by the end of this century (Kakakhel 2015).

These studies exclusively highlight direct impacts of climate change on crop production (including productivity and yield) and do not take into account impacts on livelihoods of the farmers. However, given huge macro-economic implications of climate change and agricultural production being an entry point for climate impacts, it is important to dive deep into the micro-level impacts to identify and address key climate risks. In addition to understanding future climate risks, vulnerability assessment is the key to build resilience through targeted interventions which can help to reduce identified vulnerabilities. While every region has faced with varying degrees and types of climate vulnerabilities, depending on geographical, social, economic and cultural

\footnotetext{
${ }_{1}$ A value chain is a cumulative process through which a product gains value at each step before reaching end users.
}

features, a one-size-fits-all solution cannot work (Hinkel 2011). Hence, there arises a need for vulnerability assessments that are specific to location and sector that can guide practitioners and policy makers to devise and implement targeted policy actions (Panthi et al. 2016).

Limited literature exists on farm level livelihood vulnerabilities in Pakistan. Rehman et al. (2018) hint towards deteriorating incomes as a result of changing climate. Food security vulnerability arising out of climate change is briefly highlighted in Ullah (2017). CIAT and World Bank (2017) also highlight infrastructure damages and employment losses in the aftermath of climate extreme events. Asian Development Bank (2017) also found significantly negative impact of changing climate on the livestock, which is one of the major sources of livelihood for farmers in Pakistan. Apart from these, a major concern of the farmers now is climate impacts on crop production. Crop production in Pakistan is projected to reduce by $8-10 \%$ by 2040 as a result of increase in temperature (Dehlavi et al. 2015). In terms of adaptation, Abid et al. (2015) found that adaptation practices at local level pertains to simple measures such as changing of crop sowing date, as opposed to advance management technologies.

In this backdrop, this study focuses on understanding the climate risks and vulnerabilities facing cotton farmers in Pakistan. The findings of this paper can help generate evidence on how cotton farmers in semi-arid regions are affected by climate impacts, and more importantly, how social differentiation determines the level of vulnerability between different landholders and locations. Enhanced understanding on these issues would be beneficial in designing targeted policy interventions for building resilience of cotton farmers in the face of ever-increasing climate risks. The targeted focus on semi-arid regions is because of the fact that Pakistan's water resources are under great threat of climate change, especially in semi-arid regions (Salik et al. 2015).

The paper is organized as follow; Sect. 2 details the methodology adopted for this study, Sect. 3 presents extensive discussion on results and Sect. 4 concludes the paper with policy recommendations for enhancing resilience of cotton farmers, to climate risks.

\section{Data and methodology}

This research paper follows the mixed methods research approach that integrates both qualitative and quantitative tools to explore research questions in depth. The broader aim of this paper is to understand and explore climate risks facing cotton farmers for promoting climate-resilient livelihoods and economic development. In line with this, the paper will address the following two research questions: 
a. What are the current and future climate change risks at the cotton production stage?

b. What are some of the factors of differential vulnerability across various socio-economic groups and locale?

We started our analysis with identification of future climate risks for cotton production in Pakistan and particularly for study sites, using a global gridded crop model called EPIC (Environmental Policy Integrated Climate Model) (Williams et al. 1989) which is an agro-ecosystem model running with a daily time step. It simulates crop development and yield, hydrological, nutrient and carbon cycles and a wide range of crop management activities. It takes inputs of minimum and maximum temperature $\left({ }^{\circ} \mathrm{C}\right)$, precipitation $(\mathrm{mm})$, global radiation $\left(\mathrm{MJ} \mathrm{m}^{-2}\right), \mathrm{CO}_{2}$ concentration, different soil properties, crop heat requirement. In addition, it also takes different parameters related to soil properties and crop management as input. The data used for this paper was produced as a part of ISIMIP (Inter-Sectoral Impact Model Inter-comparison Project) initiative (Warszawski et al. 2014).

For these simulations, underlying assumptions include the use of Representative Concentration Pathway (RCP) 8.5 scenario, the use of Shared Socio-Economic Pathway (SSP) 2 scenario, the representation of full irrigation, and the representation of $\mathrm{CO}_{2}$ fertilization. In ISIMIP, all crop models (including EPIC) are forced with only five Global Climate Models (GCMs) which are HadGEM2-ES, MIROC-ESMCHEM, IPSL-CM5A-LR, GFDL-ESM-2 M and NorESM1$M$. Hence, the present analysis is based on the ensemble of these five climate models which is presented by taking the relative difference of four future period (2016-2035, 2036-2055, 2056-2075, 2076-2095) against historical period of 1981-2000. Spatially averaged future yields are also presented for the provinces of Punjab and Sindh which together accounts for more than $95 \%$ of country's cotton production. The data from a global gridded crop model EPIC, forced with five different global climate models (GCMs) runs is obtained from ISIMIP (Inter-Sectoral Impact Model Inter-comparison Project) database (Warszawski et al. 2014). For this simulation, underlying assumptions include the use of Representative Concentration Pathway (RCP) 8.5 scenario, the use of Shared Socio-Economic Pathway (SSP) 2 scenario, the representation of full irrigation, and the representation of $\mathrm{CO}_{2}$ fertilization. In earlier literature, RCP 8.5 and SSP2 are both referred as 'business as usual' and 'middle of the road', respectively (Fricko et al. 2017). Moreover, among the four IPCC AR5 scenarios, RCP 8.5 is the highest emission scenario.

For farm level climate impacts information, we carried out an extensive survey of 436 farming households (cotton farmers) in two semi-arid districts of Punjab province (see full map in "Appendix 1"). The questionnaire was composed of close-ended questions related to household (household members, education, gender ratio) and farm (irrigation pattern, type of crops, level of production, climate impacts) level information. Key Informant Interviews (KIIs) and Focused Group Discussions (FGDs) were also done to gain further insights into the vulnerability at community level. Dera Ghazi Khan (DGK) and Faisalabad (FSD) were selected as study sites, based on their high contribution to the total cotton production of the country ( $42 \%$ of the cotton production in semi-arid regions in Punjab comes from these two districts). Three union councils (UC) were selected in DGK (namely, Kala, Mana Ahmadani and Mor Jhangi) and one in FSD (namely 91), based on their cotton production averages in the last 10 years. The selection of UCs was carried out to capture the diversity in climate risks and vulnerabilities within the study sites, with DGK UCs (Kala, Mana Ahmadani, Mor Jhangi) being sensitive to hill torrent and riverine flooding, while FSD UC (91) to heat extremes. The detailed description of the UCs is presented in "Appendix 2".

A sampling framework was developed in collaboration with the local (district level) agriculture department. A full list of cotton farmers (140-160 per UC) was developed for each UC and then a minimum of 100 randomly selected farmers were interviewed in each UC. To ensure that the survey captured different land tenure systems as well, the following categorization was made for each UC: landless farmers (tenants, ${ }^{2}$ sharecroppers ${ }^{3}$ and contractors ${ }^{4}$ ) small farmers (holding less than 12 acres of land), medium farmers (holding more than 12 acres but less than 25 acres) and large farmers (holding more than 25 acres). ${ }^{5} \mathrm{~A}$ minimum of 75 landholders ${ }^{6}$ and 25 in each UC were interviewed. The category-based data allowed us to make comparisons across different landholdings and location.

Table 1 further elaborates the sample size as per each category of farmers. While DGK has a greater share of cotton production than FSD, 75\% of the sample was selected from DGK whereas FSD accounted for $25 \%$ of the sample.

\footnotetext{
$\overline{2}$ A person who occupies a land rented from a landlord.

3 A tenant farmer who gives a part of each crop as rent.

${ }^{4}$ A daily wage labourer working for landholder under a seasonal contract.

5 The categorization is done based on the official categories of different farmers done by the Pakistan Bureau of Statistics.

${ }^{6}$ It is also important to note that classification of farmers was done on the basis of total landownership and not on cotton cultivation area as it is difficult to find farmers cultivating cotton on more than 25 acres of land.
} 
Table 1 Sample size based on land tenure system

\begin{tabular}{lrrrrr}
\hline & \multicolumn{3}{l}{ Union councils } & Total \\
\cline { 2 - 5 } & 91 & Kala & $\begin{array}{l}\text { Mana } \\
\text { Ahmadani }\end{array}$ & Mor Jhangi & \\
\hline Landowners & 77 & 78 & 79 & 75 & 309 \\
Sharecroppers & 10 & 7 & 8 & 9 & 34 \\
Tenant and & 11 & 20 & 15 & 10 & 56 \\
$\quad \begin{array}{l}\text { employed as wage } \\
\text { labourers }\end{array}$ & & & & & \\
Contractors & 9 & 10 & 8 & 10 & 37 \\
Total & 107 & 115 & 110 & 104 & 436 \\
\hline
\end{tabular}

\subsection{Calculation of vulnerability index}

Both top-down (e.g. climate modelling-based approaches) and bottom up approaches (focus on what causes communities to be vulnerable) exist to study climate vulnerabilities (Hinkel et al. 2014; Dessai and Hulme 2004; Van Aalst et al. 2008). Although a combination of both would be an ideal situation to identify vulnerabilities, lack of site-specific climate data allowed us to opt a bottom-up approach to identify climate vulnerabilities facing cotton farmers. One of the major advantage of using a bottom-up approach is that it helps in the identification of vulnerable groups and differences in vulnerabilities (even at small spatial scale) (Hinkel et al. 2014).

Moreover, to carry out vulnerability assessment, we followed the vulnerability framework defined in IPCC AR4 i.e.

Vulnerability $=f$ (exposure, sensitivity, adaptive capacity)

This implies that vulnerability of an individual or household is directly proportional to exposure and sensitivity, whereas it is inversely proportional to adaptive capacity. This relationship has been endorsed by various experts including Adger (2006); Weis et al. 2016; Metzger and Schröter (2006), etc. Exposure in particular, is related to the changes in climatic parameters (their intensity and frequency) and its potential impacts on resources. It answers the question of 'what is exposed?' and refers to the presence of people, livelihoods, species or ecosystems, environmental services and resources, infrastructure, or economic, social, or cultural assets in places that could be adversely affected (IPCC 2014). On the other hand, sensitivity is more dependent on socio-economic factors (gender, decision making power, mobility options, community structure, etc.), that may or may not reduce the adverse impacts of climate change (Cardona et al. 2012). Adaptive capacity plays a positive role in decreasing vulnerability against climate threat through adjustments in current behaviours. Some major attributes of adaptation include education level, networks (that promotes social learning and knowledge exchange), access to economic resources, livelihood diversification, social support institutions, etc. (Weis et al. 2016).

After selecting the proxy variables for Exposure, Sensitivity and Adaptive capacity ("Appendix 4"), we normalised the variables based on the functional relationship of variables with vulnerability, using min-max normalisation (Iyengar and Sudarshan 1982). In case of a positive relation (for example vulnerability vs. exposure and sensitive capacity), Eq. 1 was used, whereas Eq. 2 was used in case of negative relationship (for example, vulnerability vs. adaptive capacity).

$Y_{i j}=\frac{X_{i j}-\min \left(X_{i j}\right)}{\max \left(X_{i j}\right)-\min \left(X_{i j}\right)}$,

$Y_{i j}=\frac{\max \left(X_{i j}\right)-X_{i j}}{\max \left(X_{i j}\right)-\min \left(X_{i j}\right)}$,

where $X_{i j}$ denotes the value of indicator $j(j=1,2,3 \ldots n)$ in the $i$ village $(i=1,2,3 \ldots n)$ and $Y_{i j}$ is the normalised score. The normalised values lie between 0 and 1 .

In the next step, equal weights were assigned to each indicator using simple average of normalised score and vulnerability index was obtained using Eq. 3:

$\mathrm{VI}=\frac{\sum_{j} X_{i j}+\sum_{j} Y_{i j}+\sum_{j} Z_{i j}}{K}$,

where $X_{i j}, Y_{i j}$ and $Z_{i j}$ are indicators used as proxy variables for sensitivity, exposure and adaptive capacity. The vulnerability score obtained tells us the comparative vulnerabilities across various households. Using this methodology, we have derived comparative vulnerabilities:
a. Based on UCs
b. Based on landholding

To obtain a score based on each UC or landholding, we aggregated the sum of individuals in a particular UC or landholding. The final score for each component explains the level of vulnerability of people residing in a particular UC. UCs and Landholders were then ranked based on the vulnerability score. First rank represents extreme vulnerability, whereas vulnerability decreases with the increase in rank (5th rank = lowest vulnerability). The value of each component (Exposure, sensitivity and adaptive capacity) ranges between 0 and 1 , where 1 means most vulnerable and 0 means least vulnerable.

Finally, in terms of limitations, this paper focuses on two districts only and the findings cannot be generalized for Punjab or Pakistan. The findings, however, are reflective of the overall situation in similar regions. 

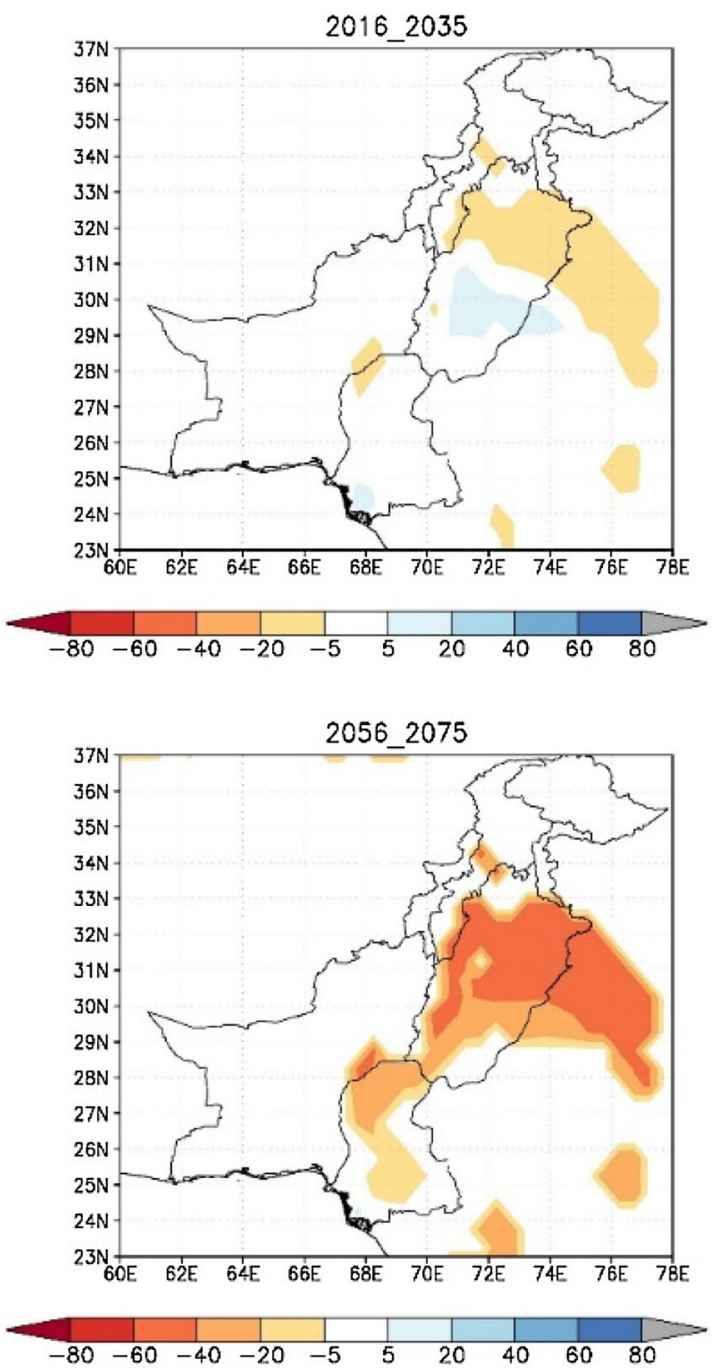
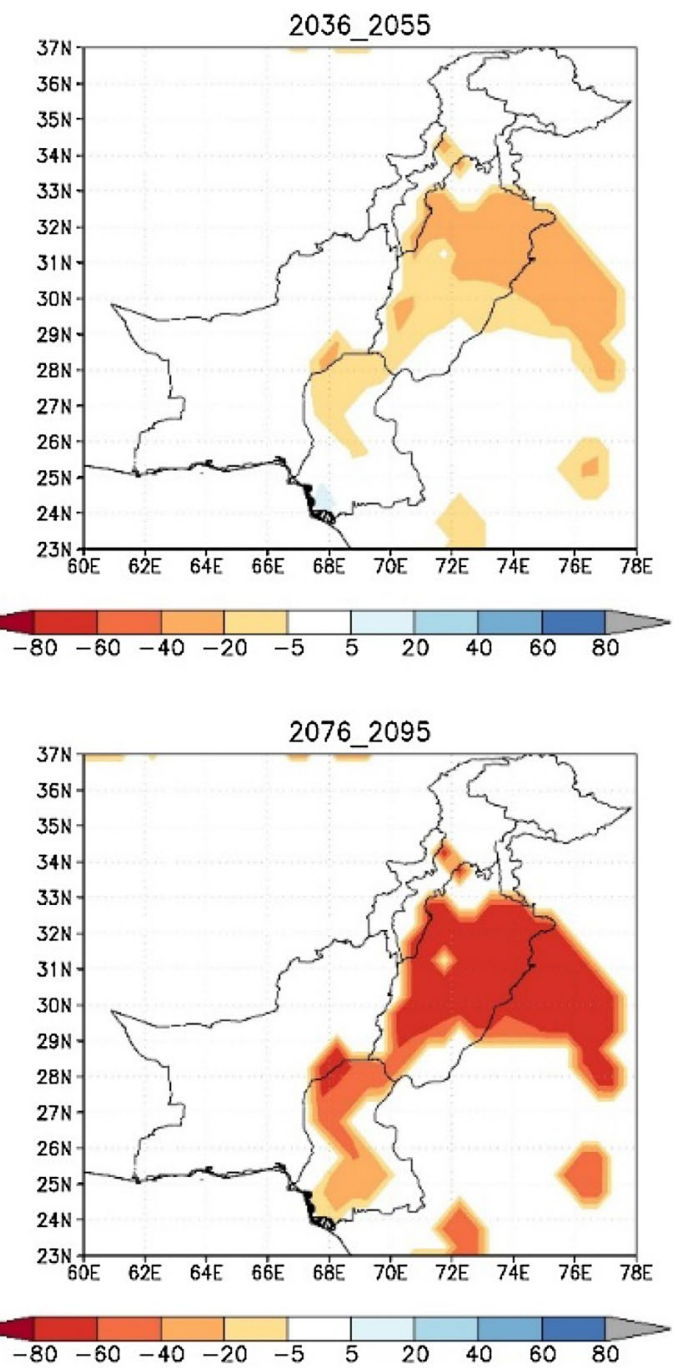

Fig. 1 Mean projected relative changes (in \%) in cotton yield relative to 1981-2000 for Pakistan using global gridded crop model EPIC forced by HadGEM2-ES, MIROC-ESM-CHEM, IPSL-CM5A-LR, GFDL-ESM-2M, NorESM1-M

\section{Results and discussion}

\subsection{Future cotton production trends}

Cotton production provides a direct entry point for climate impacts, which then trickle down to the associated value chains (Batool and Saeed 2017). We have developed the impact modelling for the cotton crop to see how cotton yield might change over time under a changing climate.

Figure 1 depicts future changes in the cotton yield over Pakistan relative to the base period 1981-2000, by taking the average of the whole ensemble (EPIC forced with 5 GCMs), for four different time slabs. As mentioned earlier, RCP 8.5 is the most extreme scenario in the suite of scenarios developed for IPCC AR5. We based our results on this scenario because it is also called as business-as-usual scenarios. The negative impacts of climate change on cotton yield start to appear right from the first-time slab (2016-2035) in northern region of Punjab. However, it is important to note that there is a slight increase in the central to southern Punjab region (Blue area) which is mainly attributed to the effects of $\mathrm{CO}_{2}$ fertilization (McGrath and Lobell 2013), which tends to have a positive effect on crop yield (depending on crop type and other factors). However, a consistent decrease in the cotton yield is witnessed in other time slabs towards the end of the century. In the last time slab from 2076 to 2095, an acute reduction of around $60-80.0 \%$ can be seen in most of the cotton producing areas of Punjab and Sindh, especially in Punjab, which accounts for $80.0 \%$ cotton production of the country. 


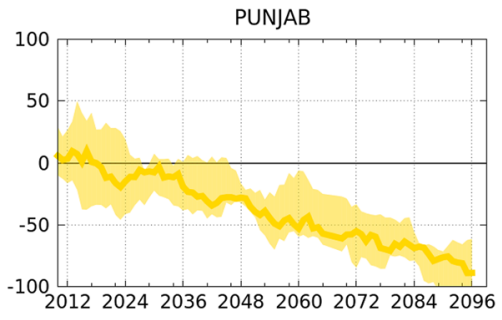

Fig. 2 Future change in cotton yield in Punjab calculated as relative difference (in \%) from the annual averaged value of historical period (1981-2000)

As mentioned in Sect. 2, the purpose of analysing the data from global crop model is to have an idea about the future impact of global warming on the yield of cotton crop at the national level in future. Since the provinces of Punjab and Sindh together accounts for more than $95 \%$ of the country's cotton production, hence we show future yield of cotton averaged over these two province in Fig. 2 as relative difference (in \%) from the base period. These are plotted by taking the spatial average of annual cotton yield over the provinces of Punjab and Sindh. A moving average of 10 years has been applied to smoothen the data by removing year-to-year variability. The analysis is carried out by taking the relative difference of four future period (2016-2035, 2036-2055, 2056-2075, 2076-2095) against historical period of 1981-2000. The dark lines represent median of the ensemble, whereas the shaded area represents the full range of the ensemble.

The figure projects a sharp decline in cotton yield by the end of this century, in a business as usual scenario, in which no significant change in mitigation or adaptation practices is made. The cotton yield is projected to decline by at least $60.0 \%$ by 2096 , which will not only affect the livelihood of the cotton farmers but the impacts will likely have a trickledown effect on the associated industries as well as the overall economy of Pakistan (Batool and Saeed 2017).

\subsection{Vulnerability assessment at farm level}

As mentioned earlier, we adopted IPCC AR4 vulnerability framework which is presented in Sect. 2. This section briefly outlines the indicators used to calculate exposure, sensitivity and adaptive capacity of the landholders and landless cotton farmers.

\subsubsection{Exposure}

Pakistan is severely exposed to climate risks as evident from climate events in the past and future threats identified in the literature (Asian Development Bank 2017). This section discusses the climate indicators used to derive the level of exposure of different landholders to climate change in our study sites.

3.2.1.1 Frequency of climate events As a measure of exposure to climate risks, we have analysed perception-based data (due to lack of downscaled climate data for each district under consideration) on the occurrence of climate extreme events in our study sites.

Table 2 provides information about the frequency and intensity of various primary and secondary climate events
Table 2 Number of times climate events experienced during the last 10 years $(\%$ in parenthesis)

\begin{tabular}{lcccc}
\hline Climate indicators & Never experienced & $\begin{array}{l}\text { Experienced 1-3 } \\
\text { times }\end{array}$ & $\begin{array}{l}\text { Experienced 3-6 } \\
\text { times }\end{array}$ & $\begin{array}{l}\text { Experi- } \\
\text { enced 6-10 } \\
\text { times }\end{array}$ \\
\hline Primary/first order climate events & $232(53.2)$ & $117(26.8)$ & $69(15.8)$ & $18(4.1)$ \\
Drought & $182(41.7)$ & $119(27.3)$ & $80(18.3)$ & $55(12.6)$ \\
Floods & $66(15.1)$ & $224(51.4)$ & $131(30.0)$ & $15(3.4)$ \\
Heat wave & $98(22.5)$ & $246(56.4)$ & $88(20.2)$ & $4(0.9)$ \\
Monsoon variability & $418(95.9)$ & $17(3.9)$ & $1(0.2)$ & 0 \\
Hailstorm & $33(7.6)$ & & & \\
Secondary/second order climate events/impacts & $171(39.2)$ & $184(42.2)$ & $48(11.0)$ \\
Pest attack & $195(44.7)$ & $171(39.2)$ & $62(14.2)$ & $8(1.8)$ \\
Erosion & $390(89.4)$ & $30(6.9)$ & $15(3.4)$ & $1(0.2)$ \\
Waterlogging & $409(93.8)$ & $19(4.4)$ & $5(1.1)$ & $3(0.7)$ \\
Salinisation & $189(43.3)$ & $172(39.4)$ & $65(14.9)$ & $10(2.3)$ \\
Weeds & $94(21.6)$ & $166(38.1)$ & $55(12.6)$ \\
Price shocks & $121(27.8)$ & & \\
\hline
\end{tabular}

${ }^{a}$ In context of our study, Monsoon variability refers to the changes in the monsoon rainfall, i.e. either too much rainfall in one go or excessive rainfall over a course of a few days (more than average rainfall) 
experienced by cotton farmers in DGK and FSD. At the overall sample scale, heat wave, ${ }^{7}$ monsoon variability, resultant pest attack and price shocks after these events are witnessed at a higher intensity and scale relative to other climate-related shocks. 51.4 and $56.4 \%$ of the respondents said that they experienced heat wave and monsoon variability, respectively, between 1 and 3 times during the last 10 years. Similarly, $42.0 \%$ of the respondents witnessed pest attacks more than 3 times during the last 10 years.

The data also highlights that a large proportion of respondents said that they have never experienced floods, droughts, erosion, waterlogging, etc. which provides a rationale to develop policy interventions to safeguard these farmers, who are currently not under the threat of floods and droughts, as they could be faced with such challenges with climate change in coming decades. Moreover, there is a large percentage of cotton farmers who said that they have faced pest attack, erosion, heat wave and floods more than 1 time and up to 10 times during the last 10 years.

Geographic location is a major factor determining the exposure to climate change. DGK is highly vulnerable to flood risk due to close proximity to River Indus but FSD is not exposed to any such threat. Even within DGK, proximity of communities to Indus River defines the level of exposure to floods. Moreover, some communities reported being particularly vulnerable to hill-torrent flood risk, depending on their location. Within our sample size, $22.0 \%$ of the respondents were solely affected by riverine floods while $26.2 \%$ were affected by hill torrents. $10.1 \%$ of the respondents reported to have been affected by both hill torrents and riverine floods.

Based on the data, we find that overall floods, drought, monsoon variability and heat wave (as primary indicator, leading to other issues) are the major issues faced by cotton farmers. Analysis of location based climate risks highlights that UC Kala and Mor Jhangi are more exposed to floods as compared to UC 91 and Mana Ahmadani (Table 3). These UCs have issues pertaining to heat wave and rainfall variability.

\subsubsection{Sensitivity}

Some of the factors determining the sensitivity of the cotton farmers in DGK and FSD are discussed below.

\subsubsection{Number of male and female labourers involved} in agricultural activities A large number of females are involved in agriculture in DGK and FSD. Women bring girls with them for cotton picking and the picking activity serves as a networking platform for women at village level. Num-

\footnotetext{
${ }_{7}$ Heat wave refers to prolonged period of excessive heat along with high humidity.
}

Table 3 Mean and standard deviation of reported climate events in different UCs during the last 10 years

\begin{tabular}{|c|c|c|c|c|}
\hline & 91 & Kala & $\begin{array}{l}\text { Mana } \\
\text { Ahmadani }\end{array}$ & Mor Jhangi \\
\hline \multicolumn{5}{|l|}{ Flood } \\
\hline Mean & 0 & 4 & 1 & 5 \\
\hline Std. deviation & 0.0 & 2.4 & 1.1 & 2.8 \\
\hline \multicolumn{5}{|l|}{ Drought } \\
\hline Mean & 3 & 1 & 2 & 0 \\
\hline Std. deviation & 3.2 & 1.8 & 1.9 & 0.9 \\
\hline \multicolumn{5}{|l|}{ Heat wave } \\
\hline Mean & 3 & 3 & 3 & 2 \\
\hline Std. deviation & 1.8 & 1.9 & 2.0 & 2.1 \\
\hline \multicolumn{5}{|c|}{ Monsoon variability } \\
\hline Mean & 2 & 2 & 2 & 2 \\
\hline Std. deviation & 1.6 & 1.7 & 2.0 & 1.5 \\
\hline
\end{tabular}

ber of female labourers employed (at the respondents' land) for farm activities is almost double than male labourers in case of UC 91 and Mana Ahmadani.

3.2.2.2 Percentage of farmers (respondents) affected by climate events Figure 3 below highlights percentage of sampled cotton farmers affected by various climate events in different UCs in DGK and FSD during the last 10 years. In the case of Kala, $95.7 \%$ of the respondents said that they were affected by pest attack and floods in the last 10 years, followed by heat wave, prices shock and monsoon variability. Similar climate risks have been faced by UC Mana Ahmadani. UC Mor Jhangi is more affected by floods (almost $99.1 \%$ of the respondents affected by flood), price shocks and monsoon variability. While no episode of flood has been recorded in FSD, UC 91 is more affected from pest attack (99.0\%) and heat wave (80.8\%). Heat wave is one of the many reasons for pest attacks in Pakistan (Zulfiqar et al. 2010; Ton 2011; Baig and Amjad 2014).

If we segregate our data on the basis of UCs and climate indicators, we find that there is a large proportion of cotton farmers that perceive high sensitivity to climate hazards. For example, in Table 4, we have clustered all those farmers who have witnessed the climate event at least once in the last 10 years under 'sensitive to climate change. We have also developed another category of farmers who have experienced various climate events more than 3 times during the last 10 years and labelled them as 'severely sensitive'. Then based on these, we have categorised the percentage of population of farmers exposed. Results are presented in the form of a sensitivity matrix where green represents the population exposure of less than $30.0 \%$, yellow represents population affected is greater than $30.0 \%$ but less than $50.0 \%$, and red represents more than $50.0 \%$ of affected population. 


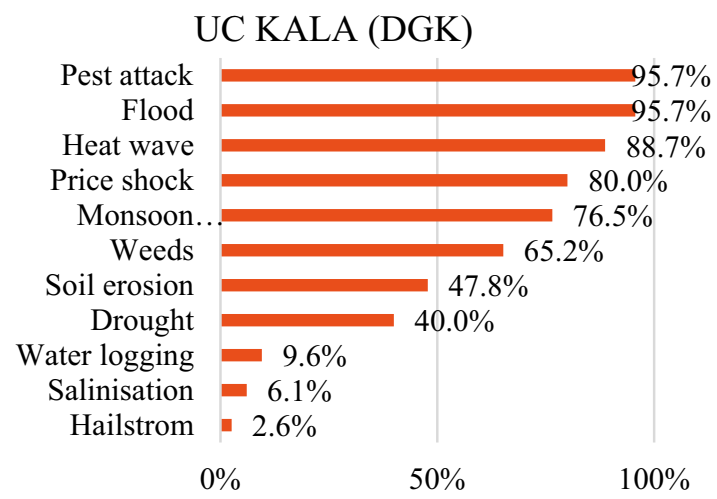

\section{UC MOR JHANGI (DGK)}

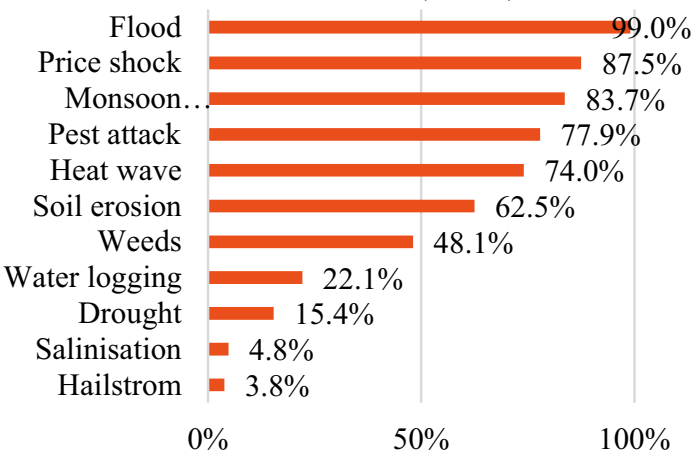

\section{UC MANA AHMADANI (DGK)}

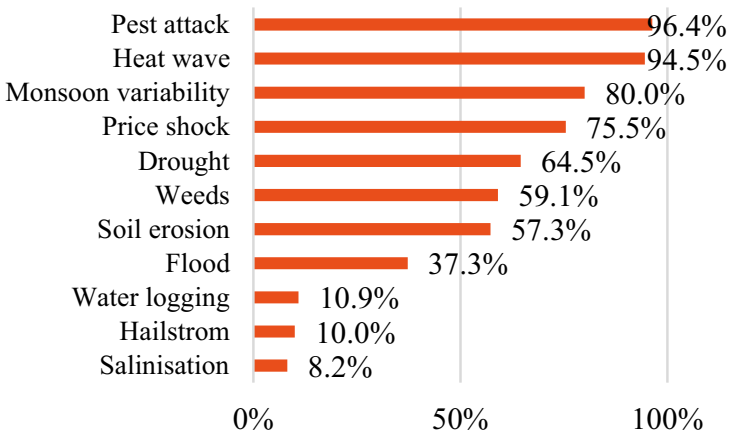

\section{UC 91 (FSD)}

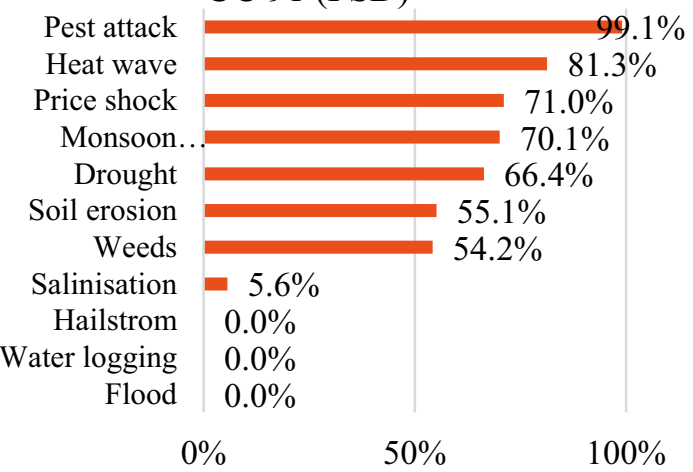

Fig. 3 Percentage of farmers reported to be affected by different climate change indicators during the last 10 years

Table 4 Level of sensitivity to climate change as per UCs

\begin{tabular}{|c|c|c|c|c|c|}
\hline \multirow[t]{2}{*}{ Climate event } & \multirow[t]{2}{*}{ Level of exposure } & \multicolumn{4}{|l|}{ UCs } \\
\hline & & 91 & Kala & Mana Ahmadani & Mor Jhangi \\
\hline \multirow[t]{2}{*}{ Drought } & Sensitivity to drought risk & $66.4 \%$ & $40.0 \%$ & $65.5 \%$ & $15.4 \%$ \\
\hline & Severely sensitive to drought risk & $44.9 \%$ & $14.9 \%$ & $21.9 \%$ & $1.0 \%$ \\
\hline \multirow[t]{2}{*}{ Floods } & Sensitivity to flood risk & N/A & $95.7 \%$ & $37.3 \%$ & $99.0 \%$ \\
\hline & Severely sensitive to flood risk & N/A & $53.0 \%$ & $1.8 \%$ & $69.2 \%$ \\
\hline \multirow[t]{2}{*}{ Heat wave } & Sensitivity to heat wave risk & $81.3 \%$ & $88.7 \%$ & $94.5 \%$ & $74.0 \%$ \\
\hline & Severely sensitive to heat wave risk & $35.5 \%$ & $33.9 \%$ & $36.4 \%$ & $27.9 \%$ \\
\hline \multirow[t]{2}{*}{ Monsoon variability } & Sensitivity to monsoon variability risk & $70.1 \%$ & $76.5 \%$ & $80.0 \%$ & $83.7 \%$ \\
\hline & Severely sensitive to monsoon variability risk & $17.8 \%$ & $20.0 \%$ & $23.6 \%$ & $23.1 \%$ \\
\hline
\end{tabular}

This table is based on the perception data. Farmers were asked about the number of years they were affected by a particular climate indicator during the last 10 years

According to these measures, in UC 9144.9 and $35.5 \%$ of the farmers are characterized as severely sensitive to risk of drought and heat wave, respectively. Conversely, farmers in UC Kala appear to be severely sensitive to floods (53.0\%), heat wave $(33.9 \%)$ and monsoon variability $(20.0 \%)$. Largely, $95.0 \%$ of the cotton farmers said that they are sensitive to flood hazard and $88.7 \%$ of the farmers are sensitive to heat wave. In Mana Ahmadani, severe sensitivity to heat wave (36.4\% of the farmers) and drought (21.9\% of the farmers) can be found. A large proportion of farmers in Mor Jhangi (99.0\%) reported that they are sensitive to flood risk while out of these, $69.2 \%$ are severely sensitive to the same. Heat wave and monsoon variability is also one of the severe risks facing farmers in Mor Jhangi. 


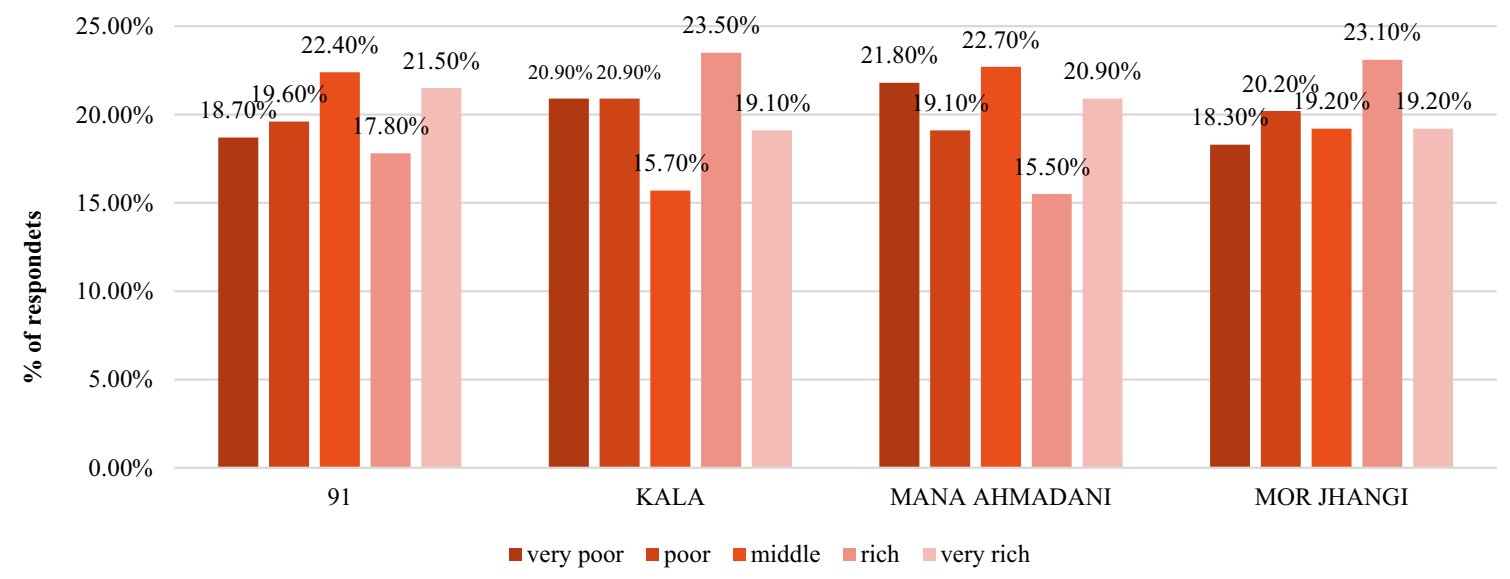

Fig. 4 Percentage of farmers as per wealth categories/UCs

\subsubsection{Percentage of population dependent on canal water} for irrigation In our sample size, we found that $45 \%$ of the farmers use only tube well water for irrigation whereas $50 \%$ of the farmers use both canal and tube well water. Due to variability in canal water availability, only around $5 \%$ of the farmers rely solely on canal water for irrigation. Segregation of data as per UC shows that Mana Ahmadani and 91 have the largest number of farmers who also use canal water for irrigation.

\subsubsection{Adaptive capacity}

A multitude of studies concludes that adaptive capacity plays a major role in reducing vulnerabilities and building resilience to climate impacts. As indicated earlier, access to education and resources (both physical and financial), livelihood diversification and social networks that promotes knowledge exchange are some of the key attributes of adaptation (Weis et al. 2016; Mendoza et al. 2014). Using these as indicators, we have built an indicator of adaptive capacity to compare differential adaptive capacities among sampled farmers and UCs.

3.2.3.1 Education In terms of education of the respondents (cotton farmers), UC Mor Jhangi and 91 has the largest number of college graduate cotton farmers (around 30-40\%). On the other hand, UC 91 has a highest percentage $(38 \%)$ of uneducated cotton farmers, followed by UC Kala (48\%).

3.2.3.2 Livelihood diversification Within our sample, agriculture is the primary source of income for $96 \%$ of the households. However, $57.3 \%$ of the households have a major second source of income. Out of those, $21.8 \%$ of the households rely on livestock for livelihood after agriculture. Other major secondary sources of income include government job (7.6\%), construction $(6.2 \%)$ and shop keeping (4.1\%). At
UC level, UC Kala has the least number of farmers dependent on only a single source of income, i.e. farming. On the other hand, UC Mana Ahmadani and Mor Jhangi has the most percentage of farmers with diversified income sources.

Similarly, small and large landholders are more inclined towards income diversification, according to our sample. There is, however, no clear trend in case of landless farmers.

3.2.3.3 Wealth status To derive sensitivities based on wealth status, we have calculated the wealth index. The methodology has been explained in "Appendix 3". Wealth index divides our respondents into five categories, i.e. very rich, rich, middle, poor and very poor. Landless farmers are categorised into very poor and poor categories. Small and medium farmers are represented in poor, middle and rich category whereas large landholders are mostly categorised into very rich category (see "Appendix 3").

As we are interested to compare wealth differences across UCs, we find that UC Kala and Mana Ahmadani have the largest percentage of very poor and poor cotton farmers (Fig. 4). However, Kala also has the largest number of rich cotton farmers, followed by UC More Jhangi. In terms of sensitivity, interventions should be targeted at more vulnerable farmer's groups, i.e. very poor and poor.

3.2.3.4 Access to financial services and post-disaster compensation Out of a sample of 436 farmers, only $34.4 \%$ have a bank account. $39.7 \%$ of farmers said that they have access to crop loans and insurance. However, almost $18.0 \%$ of the farmers reported that they do not prefer to take loans despite having access to financial services. Major reasons cited for not taking loans is high interest rates on borrowing and low capacity to return loans with interest. A small proportion (1.0\%) of the respondents also reported religious reasons for not taking loans. 
Fig. 5 Results of the vulnerability index (comparative bar chart)

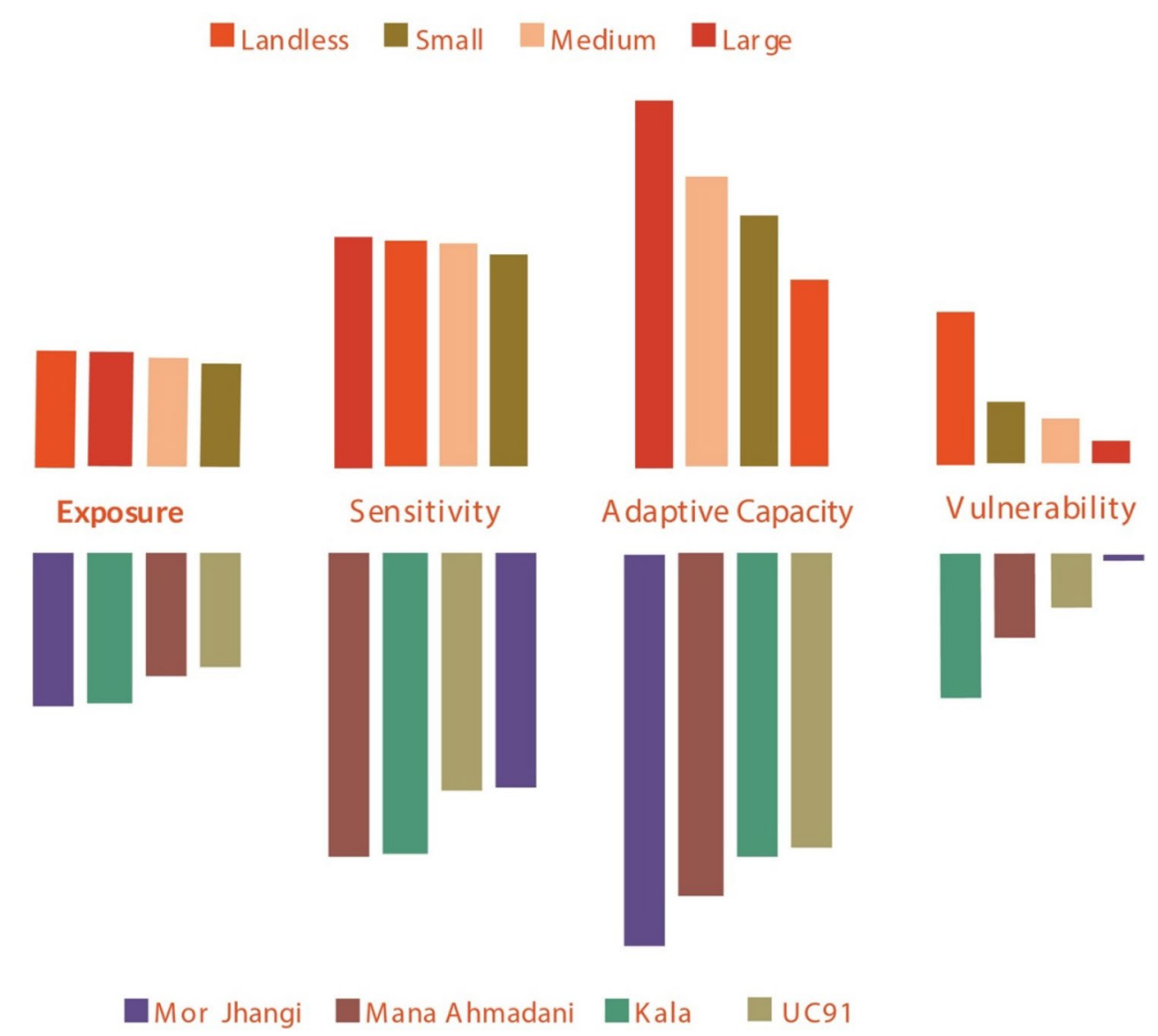

The level of compensation after flood events for each $\mathrm{UC}$ is directly proportional to the severity of the flood. For example, a high number of farmers received compensation after 2010 floods in More Jhangi (90.0\%) and Kala (52.2\%) as compared to farmers in Mana Ahmadani (13.2\%).

3.2.3.5 Access to weather information With regards to weather information, $81.7 \%$ of the total respondents reported that they receive weekly or monthly updates on weather. There is a statistically significant relationship (correlation is significant at the 0.05 level; $p$ value 0.021 ) between land size and receipt of weather information such that the number of farmers who receive monthly/weekly updates increase with the increase in the size of land. For example, $79.0 \%$ of small farmers said they receive weather updates as opposed to 85.5 and $92.2 \%$ of medium and large farmers.

3.2.3.6 Early warning In our sample, only $12.4 \%$ of the farmers from flood-affected areas reported that they had received warning prior to the 2010 flood. Among those who reported to have been warned, $83.6 \%$ said that the warning included information about the severity of flood. While UC Kala and Mor Jhangi had severe episodes of flooding in 2010, 32.2\% of the respondents from Kala and $16.3 \%$ from Mor Jhangi reported that they did not receive a warning before the flood.

\subsection{Vulnerability Index}

Since the main objectives of this paper is to see how climate vulnerabilities differ across various groups of farmers and UCs. In this section, we will analyse if there are any differences in vulnerability to climate change among different groups of landholders (small, medium and large) as well as farmers across different UCs. The relationship used for the calculation of vulnerability Index is presented in 'Data and Methodology' section. The proxy variables used to calculate vulnerability index are discussed in detail in previous sections. Functional relationship of these variables with elements of vulnerability is defended in "Appendix 3". Appendix 4 explains the steps used to derive the vulnerability index.

\subsubsection{Comparative vulnerabilities across different landholdings}

Figure 5 summarises the overall results of the vulnerability index. The value of each component ranges between 0 to 1 , where 1 means most vulnerable and 0 means least vulnerable. The figure shows that landless farmers are most vulnerable to climate change, followed by the categories of small landholders, medium landholders and large landholders. The 
vulnerability of landholders is related to the level of adaptive capacity as provided by access to financial services, strong networks which allows them to gain knowledge on new and adaptive agricultural practices, etc. Larger landholders are more likely to have access to these sources of adaptive capacity whereas small landholders and landless farmers are less likely to have large social networks, access to credit, or other assets such as livestock.

Based on the components of vulnerability, we also find that there is less variation in exposure and sensitivity to climate change between landholders and landless. On the other hand, large differences in adaptation were found among both these groups which suggests that adaptation capacity shapes vulnerability to climate change in the case of landholders and landless cotton farmers in semi-arid regions of Pakistan. While exposure and sensitivity to climate change are partly determined by external factors such as household dependency ratio and number of climate events experienced at farm level, adaptation decision-making can be promoted through targeted policy interventions that build institutional capacities and promote knowledge creation and sharing.

\subsubsection{Comparative vulnerabilities across UCs}

We find that farmers from UC Kala are the most vulnerable to climate change, followed by Mana Ahmadani, 91 and Mor Jhangi. A higher level of vulnerability implies high exposure and sensitivity to climate change coupled with low levels of adaptive capacity to cope with climate change.

UC Kala is highly exposed to flood risks and has a relatively low percentage of farmers with livelihood diversification (45.0\%), has larger households (having up to 20 members) and the highest number of non-educated cotton farmers. Similarly, Mana Ahmadani is also highly vulnerable to several climate change, including monsoon variability, drought and heat wave that lead to pest attacks. A major percentage of the farmers $(82.7 \%$ ) are dependent on canal water for irrigation which makes Mana Ahmadani highly sensitive to climate change. UC 91 has almost the same characteristics as Mana Ahmadani and is particularly vulnerable to heat stress. But since the level of exposure and sensitivity is not as high, this UC has a relatively lower vulnerability score.

On the other hand, farmers in Mor Jhangi, who are the most affected in terms of floods (as shown by exposure) is found to be least vulnerable as compared to other UCs. This is due primarily to the relatively high adaptive capacity of the farmers in this UC as Mor Jhangi has the highest number of college graduate farmers. It also has the highest rate of livelihood diversification primarily because of high risk of flood every year due to which people do not rely solely on agricultural income.

\section{Conclusion and way forward for promoting climate resilient cotton production in Pakistan}

The findings of this paper provide crucial policy entry points, which can help build resilience of the cotton farmers in Pakistan that are under continued threat of climate change. Cotton sector has suffered huge losses as a result of adverse impacts of climate in the past few years and will continue to be affected by large extent, as depicted by our climate projections, if adaptation measures are not taken.

While it is crucial to understand underlying features of vulnerability to promote adaptation, we find that vulnerability to climate change decreases with increased size of landholding. More importantly, wealth plays an important part in promoting adaptation decisions at household level but it does not always ensure adaptation decisions. In other words, not all wealth farmers adapt to climate impacts. In terms of policy, it implies that there is a need for farmer level awareness raising about climate change and its implications for agricultural productivity. Currently, there is no formal mechanism to disperse climate information top down, where it is needed the most. Information is disseminated through social networks, which benefit large landholders with large social networks. This information gap regarding current climate risks and adaptation requirements results in major losses in productivity and limited adaptation to future climate risks.

Second, despite varying level of vulnerability across landholdings, we find that all landless and landholders are vulnerable to climate change. Flood being a recurrent climate risk for Pakistan ends in loss of livelihoods of millions of farmers across the country. This not only results in massive food insecurity but also increase in poverty as medium and small landholders are further pushed down the poverty line as they fail to recover from flood damages. Crop insurance, a potential tool to deal with financial losses, is although available (through public banks) but have extremely limited outreach. In this context, crop insurance tools need to be developed that caters for both short and long-term climate related losses faced by farmers. Targeted insurance tools should be developed for landless daily wage laborers.

Finally, data collected on the access to weather information also suggest extremely limited access of farmers to weather and climate information services. Weather information infrastructure at the local level should be upgraded and efforts should be made to develop easy access of farmers to information data. Again, training of farmers on how to interpret and utilize climate data for effective adaptation is required at the local level.

Acknowledgements This study is based on the Pathways to Resilience in Semi-Arid Economies (PRISE) project, funded by Canada's International Development Research Centre (IDRC) and the UK's Department 
for International Development (DFID) through the Collaborative Adaptation Research Initiative in Africa and Asia (CARIAA). RISE holds the intellectual property rights to the research conducted for this paper.

\section{Compliance with ethical standards}

Conflict of interest On behalf of all authors, the corresponding author states that there is no conflict of interest.

Open Access This article is distributed under the terms of the Creative Commons Attribution 4.0 International License (http://creativeco mmons.org/licenses/by/4.0/), which permits unrestricted use, distribution, and reproduction in any medium, provided you give appropriate credit to the original author(s) and the source, provide a link to the Creative Commons license, and indicate if changes were made. riverine flooding from the Indus river. We interviewed cotton farmers in two villages, namely Patti Makwal and Basti Raimen, with 60 and 400 households, respectively. Major occupation of the villagers include farming, daily wage labourer and foreign employment. Major crops planted in the villages include cotton, sugarcane, rice and wheat. Patti Makwal mostly has small farmers whereas Basti Raimen has a large number of medium-sized farmers (having more than 12.5 acres of land per household). Agricultural production in this UC is particularly affected by floods, heavy rainfall and pest attack. Although majority of the farmers produce cotton, there is no cotton farmer's organization at the UC level. There are around 6-7 pesticide and fertilizer

\section{Appendix 1: Map of the study sites}

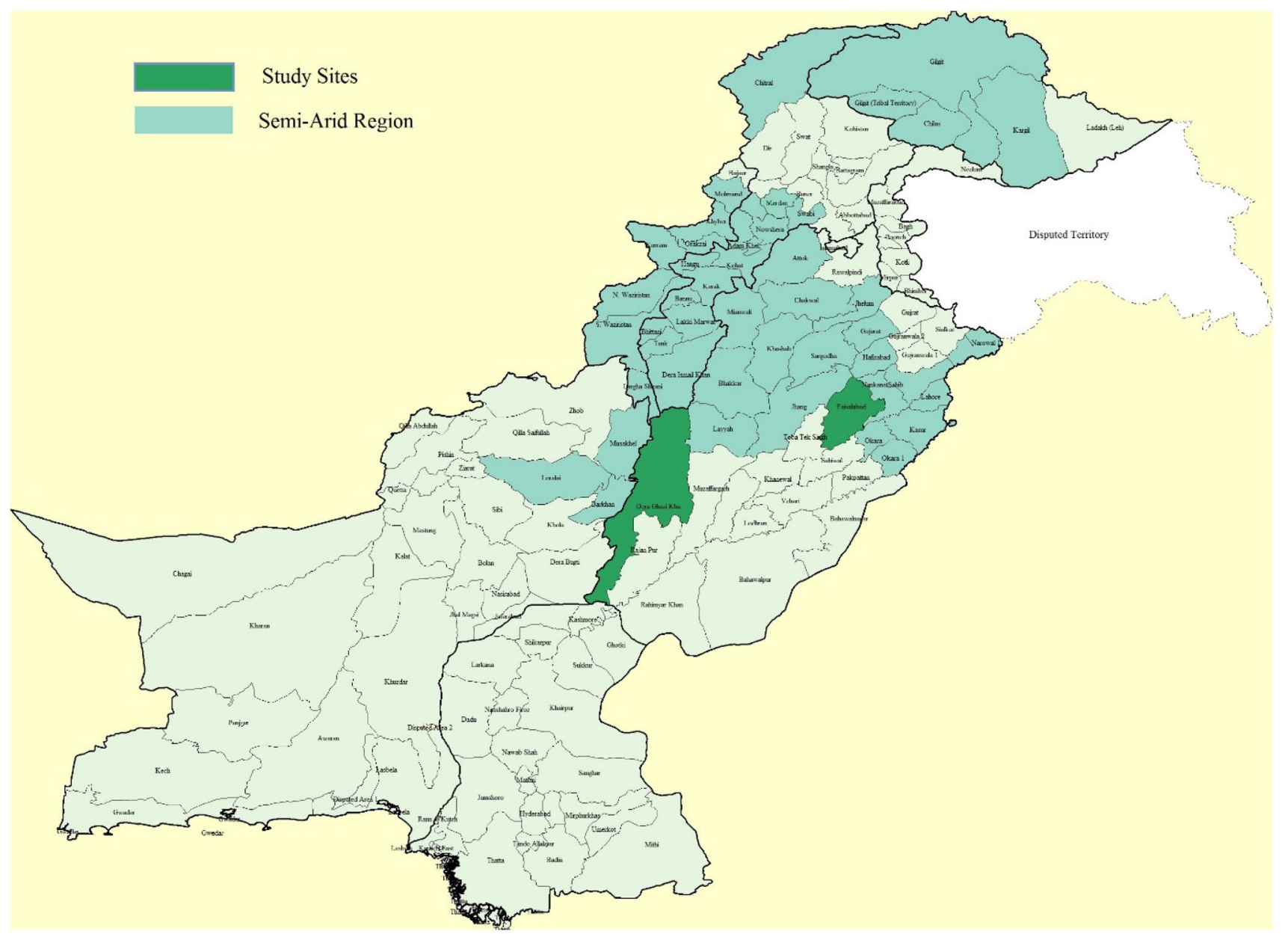

\section{Appendix 2: District profile}

\section{Dera Ghazi Khan}

Brief profile of the selected UCs of DGK is given here:

Kala is located between DGK canal and river Indus. It is affected by floods from rod khoi (hill torrents) as well as suppliers, located at a distance of $3 \mathrm{~km}$ from the village. Farmers believe that the number of providers is sufficient to cater to the demands of local farmers. However, they think that the reach of government extension department needs to be enhanced.

Mana Ahmadani is further away from the Indus river and is moderately affected by floods from hill torrents. Within 
this, we have covered a number of villages, namely Basti garbi, Bhabay wala, Kotla Ahmed khan, Basti noor wahi, Hala and Basti Foja, based on cotton production figures. The population in these villages ranges from 500 (50 households) to 6000 people (500 households). Major occupations include agricultural production, daily wage labour (farm workers and small factory workers) and foreign labour. Wheat, sugarcane, cotton and tobacco are the major crops of these villages. Major crop issues include rainfall variability, hailing and pest attack.

Mor Jhangi is located at the western side of the river Indus and is severely affected by floods from the Indus river. Basti Malana, being a large village and severely affected by 2010 floods, was the only village covered under this survey. It has an average of 1800 households and has 2500 acres of agricultural land. It has a good mix of small, medium and large sized farmers, but large farmers dominate the cotton production. The majority of agricultural land was destroyed during the 2010 flood. Increase in temperature and resultant outbreak of pest is another major issues facing crop production in this region.

\section{Faisalabad}

Cotton production has declined by $30.0 \%$ in Faisalabad since 1991. Cotton farmers have shifted to sugarcane production. We covered one UC in Faisalabad having a large number of cotton farmers. Farmers in UC 91 still produce a comparatively larger yield of cotton. Village Danabad was selected as a study site. There is not a single episode of flooding recorded since 1981. This site was chosen to assess other climate indicators such as temperature change and rainfall variability, which have significant impact on crop production and quality.

\section{Appendix 3: Indicators used for the construction of vulnerability index}

\begin{tabular}{ll}
\hline Proxy variables & $\begin{array}{l}\text { Functional relationship with } \\
\text { vulnerability }\end{array}$ \\
\hline $\begin{array}{l}\text { Exposure to climate change } \mathrm{a}^{*} \\
\text { Frequency of floods }\end{array}$ & $\begin{array}{c}\text { Vulnerability } \uparrow \text { with the } \uparrow \text { in } \\
\text { frequency of the event } \\
\text { Vulnerability } \uparrow \text { with the } \uparrow \text { in }\end{array}$ \\
Frequency of droughts & frequency of the event \\
Frequency of heat wave & $\begin{array}{c}\text { Vulnerability } \uparrow \text { with the } \uparrow \text { in } \\
\text { frequency of the event }\end{array}$ \\
Frequency of monsoon vari- & Vulnerability $\uparrow$ with the $\uparrow$ in \\
ability & frequency of the event \\
Frequency of hailstorm & Vulnerability $\uparrow$ with the $\uparrow$ in \\
& frequency of the event
\end{tabular}

\begin{tabular}{|c|c|}
\hline Proxy variables & $\begin{array}{l}\text { Functional relationship with } \\
\text { vulnerability }\end{array}$ \\
\hline \multicolumn{2}{|l|}{ Sensitivity to climate change } \\
\hline $\begin{array}{l}\text { Number of male and female } \\
\text { labourers in agricultural lands }\end{array}$ & $\begin{array}{l}\text { Vulnerability } \uparrow \text { with the } \uparrow \text { in num- } \\
\text { ber of labourers }\end{array}$ \\
\hline $\begin{array}{l}\text { Number of farmers affected by } \\
\text { Floods, droughts, heat stress, } \\
\text { monsoon variability and } \\
\text { hailstorm }\end{array}$ & $\begin{array}{l}\text { Vulnerability } \uparrow \text { with the } \uparrow \text { in } \\
\text { number of farmers affected by } \\
\text { climate events }\end{array}$ \\
\hline $\begin{array}{l}\text { Number of population } \\
\text { dependent of canal water for } \\
\text { irrigation }\end{array}$ & $\begin{array}{l}\text { Vulnerability } \uparrow \text { with the } \uparrow \text { in num- } \\
\text { ber of farmers using canal water }\end{array}$ \\
\hline \multicolumn{2}{|c|}{ Adaptive capacity of the farming household } \\
\hline $\begin{array}{l}\text { Level of education of the } \\
\text { respondents }\end{array}$ & $\begin{array}{l}\text { Vulnerability } \downarrow \text { with the level of } \\
\text { education }\end{array}$ \\
\hline $\begin{array}{l}\text { Highest level of education at } \\
\text { the household level }\end{array}$ & $\begin{array}{l}\text { Vulnerability } \downarrow \text { with the } \uparrow \text { highest } \\
\text { level of education }\end{array}$ \\
\hline Livelihood diversification & $\begin{array}{l}\text { Vulnerability } \downarrow \text { with access to off } \\
\text { farm employment }\end{array}$ \\
\hline Wealth status & $\begin{array}{l}\text { Vulnerability } \downarrow \text { with the level of } \\
\text { wealth }\end{array}$ \\
\hline Access to financial resources & $\begin{array}{l}\text { Vulnerability } \downarrow \text { with the access to } \\
\text { financial resources }\end{array}$ \\
\hline Access to weather updates & $\begin{array}{l}\text { Vulnerability } \downarrow \text { with the access to } \\
\text { weather updates }\end{array}$ \\
\hline Early warning & Vulnerability $\downarrow$ with early warning \\
\hline
\end{tabular}

${ }^{\text {a }}$ Sum of total does not add to the total number of respondents as multiple options exists for sources of information

\section{Appendix 4: Wealth index categories as per landholdings}

Following the methodology used by Vyas and kumaranayake (2016), we have constructed the wealth index, using the Principal Components Analysis (PCA). PCA helps in the identification of small uncorrelated variables in a large dataset, defines their relationship, summarizes the data and prevent loss of even minute information (Devkota et al. 2014, Filmer and Prittchet 2001). PCA can be mathematically represented as follow:

$y_{j}=\varphi_{1}\left(\frac{x_{1}-\bar{x}_{1}}{s_{1}}\right)+\varphi_{2}\left(\frac{x_{2}-\bar{x}_{2}}{s_{2}}\right)+\cdots+\varphi_{\mathrm{m}}\left(\frac{x_{\mathrm{m}}-\bar{x}_{\mathrm{m}}}{s_{\mathrm{m}}}\right)$,

where $\bar{x}_{\mathrm{m}}$ and $s_{\mathrm{m}}$ are the mean and standard deviation of asset $x_{\mathrm{m}}$, and $\varphi$ is the weight for each variable.

This division of data creates weighted components or factors that allows for interpretation of smaller components from large datasets. Table below highlights the variables used for the construction of the PCA, which includes land ownership, regular household items and access to irrigation facilities. 
Descriptive statistics

\begin{tabular}{lll}
\hline & Mean & Std. deviation \\
\hline Small farmer & 0.43 & 0.495 \\
Medium farmer & 0.11 & 0.313 \\
Large farmer & 0.23 & 0.424 \\
Tractor & 0.33 & 0.47 \\
TV & 0.48 & 0.5 \\
Radio & 0.16 & 0.368 \\
Phone & 0.57 & 0.496 \\
Smartphone & 0.39 & 0.487 \\
Computer & 0.06 & 0.245 \\
Canal water & 0.55 & 0.498 \\
Use tube well & 0.95 & 0.209 \\
Own tube well & 0.85 & 0.361 \\
Bank account & 0.34 & 0.476 \\
Weather information & 0.64 & 0.479 \\
Educated & 0.89 & 0.31 \\
Income diversification & 0.58 & 0.493 \\
Land ownership & 0.77 & 0.421 \\
Acres & 0.69 & 0.111 \\
\hline
\end{tabular}

\begin{tabular}{|c|c|c|c|c|c|c|}
\hline \multicolumn{7}{|c|}{ Total variance explained } \\
\hline \multirow[t]{2}{*}{$\begin{array}{l}\text { Com- } \\
\text { ponent }\end{array}$} & \multicolumn{3}{|c|}{ Initial eigen values $^{\mathrm{a}}$} & \multicolumn{3}{|c|}{$\begin{array}{l}\text { Extraction sums of } \\
\text { squared loadings }\end{array}$} \\
\hline & Total & $\begin{array}{l}\% \text { of Vari- } \\
\text { ance }\end{array}$ & $\begin{array}{l}\text { Cumula- } \\
\text { tive } \%\end{array}$ & Total & $\begin{array}{l}\% \text { of } \\
\text { Vari- } \\
\text { ance }\end{array}$ & $\begin{array}{l}\text { Cumula- } \\
\text { tive } \%\end{array}$ \\
\hline 1 & 764.883 & 99.638 & 99.638 & 2.47 & 13.724 & 13.724 \\
\hline 2 & 0.425 & 0.055 & 99.694 & & & \\
\hline 3 & 0.345 & 0.045 & 99.739 & & & \\
\hline 4 & 0.321 & 0.042 & 99.78 & & & \\
\hline 5 & 0.25 & 0.033 & 99.813 & & & \\
\hline 6 & 0.227 & 0.03 & 99.843 & & & \\
\hline 7 & 0.212 & 0.028 & 99.87 & & & \\
\hline 8 & 0.175 & 0.023 & 99.893 & & & \\
\hline 9 & 0.15 & 0.02 & 99.912 & & & \\
\hline 10 & 0.129 & 0.017 & 99.929 & & & \\
\hline 11 & 0.119 & 0.016 & 99.945 & & & \\
\hline 12 & 0.106 & 0.014 & 99.959 & & & \\
\hline 13 & 0.086 & 0.011 & 99.97 & & & \\
\hline 14 & 0.08 & 0.01 & 99.98 & & & \\
\hline 15 & 0.067 & 0.009 & 99.989 & & & \\
\hline 16 & 0.048 & 0.006 & 99.995 & & & \\
\hline 17 & 0.038 & 0.005 & 100 & & & \\
\hline 18 & $4.60 \mathrm{E}-16$ & $5.99 \mathrm{E}-17$ & 100 & & & \\
\hline
\end{tabular}

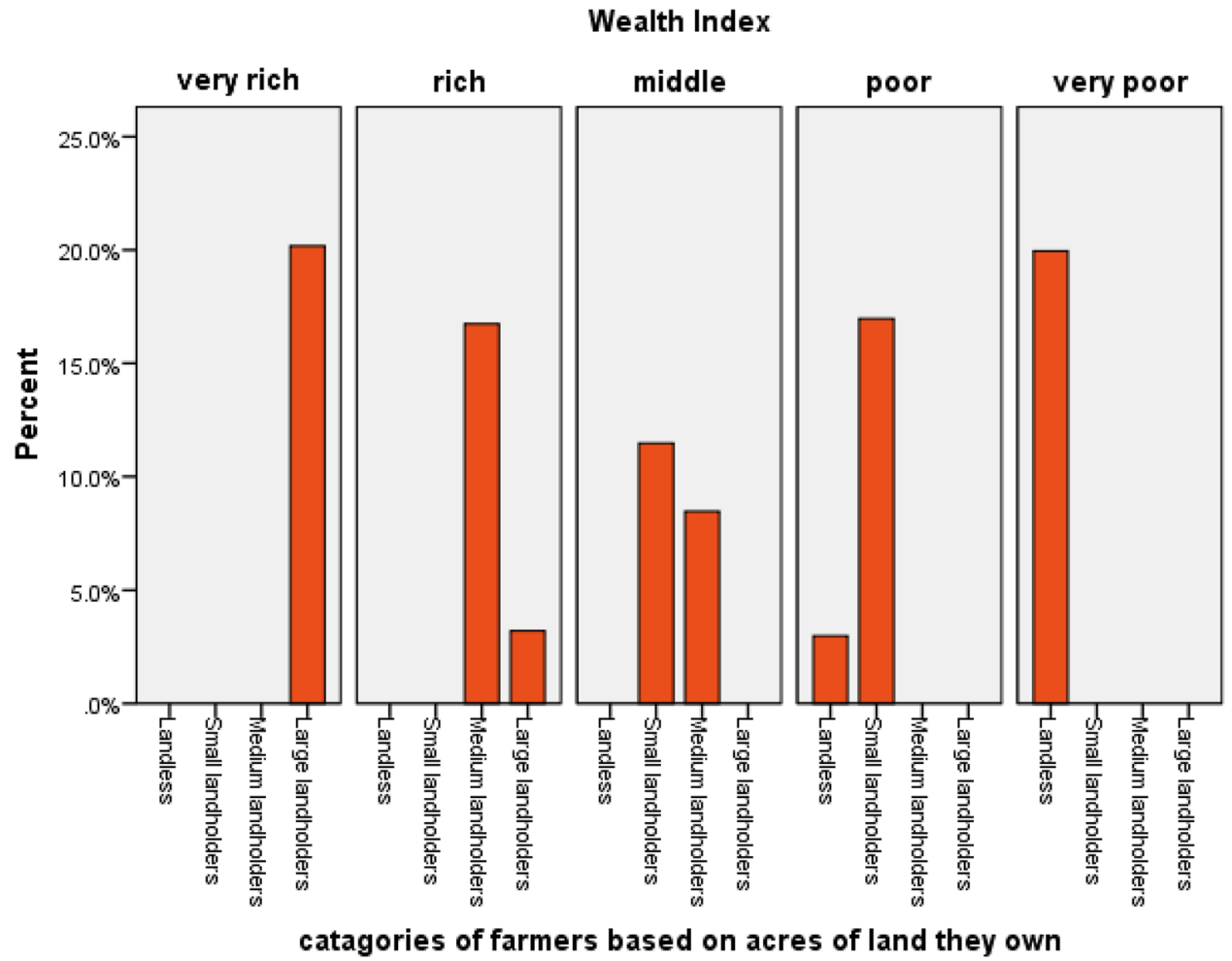




\section{References}

Abid M, Scheffran J, Schneider UA, Ashfaq M (2015) Farmers' perceptions of and adaptation strategies to climate change and their determinants: the case of Punjab province, Pakistan. Earth Syst Dyn 6:225-243

Adger N (2006) Vulnerability. Global Environ Change 16(2006):268281 (Elsevier)

Ali S, Khattak M, Khan D, Sharif M, Khan H, Ullah A, Malik A (2016) Predicting future temperature and precipitation over Pakistan in the 21st century. J Eng Appl Sci (JEAS) 35:61-76 (University of Engineering and Technology, Peshawar)

Asian Development Bank (2017) Climate change profile of Pakistan. Report. Manila, Philippines

Baig MA, Amjad S (2014) Climate change impact on major crops of Pakistan: a forecast for 2020, Institute of Business Management

Bange M (2007) Effects of climate change on cotton growth and development. The Australian Cotton Grower. June issue. Green Mount Press, Australia

Batool S, Saeed F (2017) Mapping the cotton value chain in Pakistan: a preliminary assessment for identification of climate vulnerabilities \& pathways to adaptation. PRISE working paper. Sustainable Development Policy Institute, Islamabad

Cardona OD, van Aalst MK, Birkmann J, Fordham M, McGregor G, Perez R, Pulwarty RS, Schipper ELF, Singh BT (2012) Determinants of risk: exposure and vulnerability. In: Field CB, Barros V, Stocker TF, Qin D, Dokken DJ, Ebi KL, Mastrandrea MD, Mach KJ, Plattner G-K, Allen SK, Tignor M, Midgley PM (eds) Managing the risks of extreme events and disasters to advance climate change adaptation A special report of working Groups I and II of the intergovernmental panel on climate change (IPCC). Cambridge University Press, Cambridge, pp 65-108

CIAT and World Bank (2017) Climate-Smart Agriculture in Pakistan. CSA Country Profiles for Asia Series. International Center for Tropical Agriculture (CIAT); The World Bank. Washington, D.C., p 28

Dehlavi A, Groom B, Gorst A (2015) Climate change adaptation in the indus ecoregion: a microeconometric study of the determinants, impacts, and cost effectiveness of adaptation strategies. World Wide Fund for Nature (WWF) Pakistan, Islamabad

Dessai S, Hulme D (2004) Does climate adaptation policy need probabilities? Clim Policy 4:107-128

Devkota JU, Singh S, Prajapati C, Hada B (2014) Principal components analysis of the socioeconomic conditions of biogas users - with examples from Nepal. Int J Renew Energy Res 4(3):655-664

Filmer D, Pritchett LH (2001) Estimating wealth effects without expenditure data or tear: an application to educational enrolments in states of India. Demography 38(1):115-132

Fricko O, Havlik P, Rogelj J, Klimont Z, Gusti M, Johnson N, Kolp P, Strubegger M, Valin H, Amann M, Ermolieva T, Forsell N, Herrero M, Heyes C, Kindermann G, Krey V, McCollum DL, Obersteiner M, Pachauri S, Rao S, Schmid E, Schoepp W, Riahi K (2017) The marker quantification of the Shared Socioeconomic Pathway 2: a middle-of-the-road scenario for the 21st century. Global Environ Change 42:251-267

(GoP) Government of Pakistan (2017) Economic survey of Pakistan 2016-2017. Ministry of Finance

Hinkel J (2011) Indicators of vulnerability and adaptive capacity: towards a clarification of the science policy interface. Global Environ Change 21:198-208

Hinkel J, Schipper L, Wolf S (2014) A Framework for Climate Change Vulnerability Assessments. Deutsche Gesellschaft für Internationale Zusammenarbeit (GIZ) GmbH, India
Hussain MS, Lee S (2014) Long-term variability and changes of the precipitation regime in Pakistan. Asia Pac J Atmos Sci 50(3):271-282

Ikram F, Afzaal M, Bukhari S, Ahmed B (2016) Past and future trends in frequency of heavy rainfall events over Pakistan. Pakistan J Meteorol 12(24):57-78

IPCC (2014) Climate Change 2014: impacts, adaptation, and vulnerability Part B: regional aspects. In: Barros VR, Field CB, Dokken DJ, Mastrandrea MD, Mach KJ, Bilir TE, Chatterjee M, Ebi KL, Estrada YO, Genova RC, Girma B, Kissel ES, Levy AN, MacCracken S, Mastrandrea PR, White LL (eds) Contribution of working group II to the fifth assessment report of the intergovernmental panel on climate change. Cambridge University Press, Cambridge, p 688

Iyengar NS, Sudarshan P (1982) A method of classifying regions from multivariate data. Econ Polit Wkly 17:2048-2052

Kakakhel S (2015) The Indus River Basin and climate change. Criterion Quarterly 10(3)

Khattak S, Ali S (2015) Assessment of temperature and rainfall trends in Punjab province of Pakistan for the period 1961-2014. J Himal Earth Sci 48:42-61

MacKerron D (2001) Climate change and global crop productivity. Edited by Reddy KR, Hodges HF. Wallingford, UK: CABI Publishing (2000), pp. 471. Experimental Agriculture, 37(2), 269-274

Maida Z, Rasul G (2010) Rise in summer hest index over Pakistan. Pakistan J Meteorol 6:12

McGrath JM, Lobell DB (2013) Regional disparities in the CO2 fertilization effect and implications for crop yields. Environ Res Lett 8(1):014054

Mendoza MET, The BD, Naret H, Ballaran VG, Arias JKB (2014) Assessing vulnerability to climate change impacts in cambodia, the philippines and vietnam: an analysis at the commune and household level. Environ Sci Manag 17(2):78-91

Metzger MJ, Schröter D (2006) Towards a spatially explicit and quantitative vulnerability assessment of environmental change in Europe. Reg Environ Change 6:201-216

Panthi J, Aryal S, Dahal P, Bhandari P, Krakauer NY, Pandey VP (2016) Livelihood vulnerability approach to assessing climate change impacts on mixed agro-livestock smallholders around the Gandaki River Basin in Nepal. Reg Environ Change 16(4):1121-1132

Rehman MA, Siddique BN, Hashmi N, Masud K, Adeel M, Rameez M, Khan A, Dawodd KM, Shah SAA, Karim M (2018) Climate change impact on rural livelihoods of small landholder: a case of Rajanpur, Pakistan. Int J Appl Agric Sci 4(2):28-34. https://doi. org/10.11648/j.ijaas.20180402.11

Richardson AG, Reddy KR, Boone ML (2002) Sensitivity analysis of climate change impacts on cotton production using the GOSSYM crop model. Int J Biotronics 31:25-49

Río S, Iqbal A, Cano-Ortiz M, Herrero A, Hassan L, Penas A (2013) Recent mean temperature trends in Pakistan and links with teleconnection patterns. Int J Climatol 33:277-290

Sadiq N, Qureshi M (2010) Climatic variability and linear trend models for the five major cities of Pakistan. J Geogr Geol 2:83-92

Saeed F, Athar H (2017) Assessment of simulated and projected climate change in Pakistan using IPCC AR4-based AOGCMs. Theor Appl Climatol 130:1-14

Saeed F, Almazroui M, Islam N, Khan MS (2017) Intensification of future heat waves in Pakistan: a study using CORDEX regional climate models ensemble. Nat Haz 87:1635-1647

Salik KM, Ishfaq S, Saeed F, Noel E, Syed Q (2015) Pakistan Country Situation Assessment. PRISE working paper

Salma S, Rehman S, Shah MA (2012) Rainfall trends in different climate zones of Pakistan. Pakistan J Meteorol 9(17):34-47 
Sheikh MM, Manzoor N, Adnan M, Ashraf J, Khan AM (2009) Climate profile and past climate changes in Pakistan. Research Report No. GCISC-RR-01, Global Change Impact Studies Centre, Islamabad

Siddique R, Samad G, Nasir M, Jalil H (2012) The impact of climate change on major agricultural crops: evidence from Punjab, Pakistan. PIDE Working Paper

Singh RP, Vara PV, Sunita K, Giri SN, Reddy KR (2007) Influence of high temperature and breeding for heat tolerance in cotton: a review. Adv Agronomy 93:313-385

Ton P (2011) Cotton and climate change: impacts and options to mitigate and adapt. International Trade Centre (ITC) Geneva: ITC, 2011. xii, 32 p. (Technical paper)

Ullah S (2017) Climate change impact on agriculture of Pakistana leading agent to food security. Int J Environ Sci Nat Resour 6(3):555690. https://doi.org/10.19080/IJESNR.2017.06.555690

van Aalst MK, Cannon T, Burton I (2008) Community level adaptation to climate change: the potential role of participatory community risk assessment. Global Environ Change 18(1):165-179
Warszawski L, Frieler K, Huber V, Piontek F, Serdeczny O, Schewe J (2014) The inter-sectoral impact model intercomparison project (ISI-MIP): project framework. Proc Natl Acad Sci USA 111:3228-3232

Weis SWM, Agostini VN, Roth LB, Gilmer B, Schill SR, Knowles JE, Blyther R (2016) Assessing vulnerability: an integrated approach for mapping adaptive capacity, sensitivity, and exposure. Clim Change 136(3):615-629

Williams JR, Jones CA, Kiniry JR, Spanel DA (1989) The EPIC crop growth model. Trans ASAE 32:497-511

Zulfiqar MA, Sabri MA, Raza MA, Hamza A, Hayat A, Khan A (2010) Effect of Temperature and Relative Humidity on the Population Dynamics of Some Insect Pests of Maize. Pakistan J Life Soc Sci 8:16-18 